\title{
PRECISIONES SOBRE LA INTERPRETACIÓN NOMINALISTA DE LA CIVITAS EN MARSILIO DE PADUA
}

\author{
Bernardo Bayona Aznar \\ I. E. S «Goya» de Zaragoza
}

\begin{abstract}
RESUMEN
Los esfuerzos por demostrar la influencia de la filosofia nominalista en la teoría política de Marsilio de Padua no han tenido éxito. Otras corrientes de pensamiento y escuelas filosóficas, como el aristotelismo heterodoxo, el corporativismo medieval e incluso la concepción orgánica de la sociedad tienen más influencia en el Defensor pacis, concebido y escrito varios años antes de ser compañero de Ockham en la Corte imperial de Luis de Baviera. El artículo examina los textos en los que se ha basado la interpretación nominalista del pensamiento de Marsilio. La conclusión es que la teoría de la civitas que expone Marsilio no está basada en la concepción nominalista de la sociedad. En su lucha contra la plenitudo potestatis del Papado, Marsilio construye una civitas, en la que no cabe el poder eclesiástico diferente del secular. El resultado son dos modelos de sociedad distintos: dualista el de Ockham; mucho más monolítico el de Marsilio, que no reconoce a los ciudadanos individuales ni a las partes de la civitas capacidad para actuar autónomamente.
\end{abstract}

Palabras clave: Nominalismo, civitas, universitas, multitudo, populus, individualismo social, Marsilio de Padua, Ockham.

\begin{abstract}
The efforts to show the influence of the philosophy nominalist on Marsiglio of Padua's political theory haven't been successful. Other trends of thought and philosophical schools, as the heterodox aristotelism, the medieval corporativism, even the organic idea of society are more present at the Defensor pacis, thought and written some years before Marsiglio became fellow of Ockham at the Court of the German King Ludwig IV of Bavaria. The paper examines some texts on which the nominalist understanding of Marsilio's thought has been founded. It comes to the conclusion that Marsilio doesn't explain a theory of civitas, based on a nominalist idea of society. In his struggle against plenitudo potestatis of Papacy, Marsilio builds a civitas, in which there's no place for any priestly power different from the secular one. The result is that ther'are two different kinds of society: Ockham's kind, dualist; Marsilio's, much more monolithic, without granting to individual citizens or to the parts of civitas any competence to operate autonomously.
\end{abstract}

Key words: Nominalism, civitas, universitas, multitudo, populus, social individualism, Marsiglio of Padua, Ockham.

En el pensamiento del Medioevo las relaciones entre los individuos y el conjunto de la sociedad no es una cuestión teóricamente relevante. Los ciudadanos lo son corporativamente, no personalmente ${ }^{1}$. El latín medieval ofrece un amplio repertorio de términos para denominar la

1 Véase, BLACK, A., «The individual and society, BURNS, J. H. (ed.), The Cambridge History of Medieval Political Thought, c.350-c.1450, Cambridge, Cambridge University press, 1991, p. 591; también ULLMANN, W., The individual and Society in the Middle Ages, London, Methuen, 1967. 
agrupación o asociación humana (universitas, societas, communitas, corpus, multitudo, congregatio, colletio, coetus, collegium), mientras que es significativamente escaso el utilizado para referirse al individuo y expresar la relación entre éste y el conjunto social. Apenas se encuentran palabras para lo 'individual': el término más empleado por los escolásticos es «persona singularis»; que unas veces es denominada también «civis» y, otras, «fidelis», según se acentúe el aspecto civil o eclesial de su pertenencia a la comunidad.

Sólo con el nominalismo cobran importancia los individuos. Además, la querella sobre la pobreza meritoria involucra no sólo el estatuto de la propiedad (dominium), individual o colectiva, sino el de la orden franciscana y su existencia jurídica como tal. Para Ockham, la Orden sólo consta, en realidad, del conjunto de miembros que la componen y que, contrariamente a lo sostenido por el papa Juan XXII, no constituyen una persona moral, o ficta. Una asociación o reunión de individuos - sea la Orden o cualquier otra forma de comunidad- «no es una de distinto modo que el Estado es llamado uno, que el pueblo, el ejército incluyendo a hombres y caballos (...), que el reino, que la totalidad, que el mundo son llamados unos ${ }^{2}$. La noción de comunidad política que ofrece Guillermo de Ockham la constituye el conjunto de los individuos que la componen, sea llamada «universitas mortalium», «una civitas» o «unum collegium». No se puede, pues, hablar de unidad, ni aun en el caso de la humanidad entera, más que de manera impropia: «Aliquid est unum impropie et large, sicut regnum dicitur unum, vel populus unus» ${ }^{3}$. El pueblo, considerado como un agregado de individuos, es quien tiene poder instituyente ${ }^{4}$. En definitiva, Ockham rechaza la noción de personalidad colectiva o persona moral, que sólo tiene un significado metafórico, y muestra reservas hacia el principio de representación de las voluntades individuales. Para él, las instituciones, civiles o eclesiásticas, en realidad, no tienen intenciones distintas de las de la multitud de individuos que las integran. El poder de establecer instituciones reside en el pueblo como agregado de individuos, ya que los individuos racionales son, si se habla de sociedad, los únicos que tienen existencia real. Igualmente, la Iglesia no puede ser representada por el Papa, ni tampoco por los obispos, separados del conjunto de los creyentes ${ }^{5}$. La recusación de la idea de comunidad como totalidad, aplicada a cualquier sociedad humana, sería el aspecto característico del nominalismo político, si es que puede hablarse de tal teoría.

El hecho de que Marsilio de Padua se refugiara en la Corte del emperador Luis de Baviera, como poco más tarde haría Ockham, y de que ambos pusieran su ingenio y su pluma al servicio de la causa imperial frente a la ingerencia del Papado en el poder temporal, ha favorecido la tendencia a asimilar la teoría política del primero con la filosofia del máximo representante del nominalismo. Esta agrupación filosófica entre ambos autores resulta superficial. No tiene en cuenta que el Defensor pacis fue concebido y escrito varios años antes de

2 Además, la relación no es una cosa distinta de la cosa singular, es sólo un término; por tanto, cualquier relación entre los hombres — por ejemplo, la paternidad- es una «vox quae est ad aliquid, et non res absoluta» (OCKHAM, Suma de logica, I, c. 49).

3 BAUDRY, L., Guillaume d'Occam: sa vie, ses oeuvres, ses idees sociales et politiques, Paris, J. Vrin, 1949, p. 175 .

4 Véase, QUILLET, J., «Community, counsel and representation», BURNS, J. H. (ed.), The Cambridge History of Medieval Political Thought, o. c., p. 538; e IDEM, «Nominalismo político», en RAYNAUD, Ph. y RIALS, S. (eds.), Diccionario de Filosofia política, Akal, Madrid, 2001, p. 568.

5 Llega a decir que es absurdo hablar de representante o delegado: «Quia si Ordo Fratrum minorum est persona repraesentata et imaginaria, eadem ratione ecclesia et quaelibet communitas esset persona repraesentata et imaginaria, quod est absurdum, quod enim est tantum repraesentatum et imaginarium est fantasticum, et non est in re extra animam», OCKHAM, Opus nonaginta dierum, LXII; véase, QUILLET, J., "Community, counsel and representation», en o. c., p. 562 . 
que Marsilo y Ockham se reunieran bajo la protección imperial ${ }^{6}$; ni tampoco advierte las tensas relaciones que mantuvieron por causa de sus discrepancias filosóficas, que Ockham expresa en la tercera parte del Dialogus y Marsilio replica en el Defensor minor ${ }^{7}$. A pesar de que los contemporáneos comentaban la influencia de Marsilio sobre los franciscanos, o de Ockham sobre Marsilio ${ }^{8}$, estos filósofos venían de caminos diferentes y «no andaban en la misma dirección» ${ }^{9}$. Había margen para la cooperación en la causa común a favor del Emperador, pero tenian notables diferencias filosóficas y políticas.

Según la lectura nominalista de la filosofía marsiliana, la inspiración individualista de ésta permitiría explicar la inclinación democrática de la obra del Paduano, expresada en la identificación del:legislador con la universitas civium y la fundamentación de la civitas en la voluntad del conjunto de los ciudadanos. Dice Marsilio, en el Defensor pacis, que el legislador es «el pueblo, o sea, todos los ciudadanos» y se refiere asimismo a «la asamblea general de los ciu-

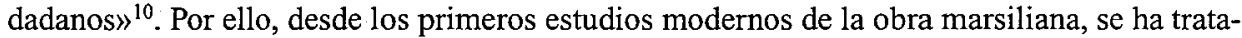
do de reconocer el influjo nominalista en algunos aspectos característicos de la concepción social de Marsilio ${ }^{11}$ y se han buscado explicaciones para sortear los rotundos argumentos que esgrime en favor de la unidad del poder. Así, por ejemplo, se ha explicado la ruptura entre la formación averroísta juvenil ${ }^{12}$ y el pensamiento político maduro por una supuesta crisis religiosa, que habría sido provocada por el nominalismo y el voluntarismo, de los que Marsilio habría extraído consecuencias políticas y religiosas que otros no se habrian atrevido a sacar ${ }^{13}$. Diversos autores han seguido después tratando de encontrar en la obra de Marsilio huellas de un movimiento que le era tan cercano; pero, hay que añadir, sin poder ofrecer grandes resultados.

6 La llegada de Ockham a la Corte del Emperador se produjo en 1328, mientras que el Defensor pacis se terminó el 24 de junio de 1324 y hay motivos fundados para pensar que su elaboración estaba ya en proceso en la década anterior, como se explica en BAYONA, B. «Precisiones sobre el corpus marsiliano. Las obras de Marsilio de Padua», J. SOLANA DUESO, E. BURGOS DÍAZ y P. L. BLASCO AZNAR (eds.), Las raíces de la cultura europea. Ensayos en homenaje al profesor Joaquín Lomba, Zaragoza, Prensas Universitarias de Zaragoza e Institución «Fernando el Católico», 2004, p. 161.

7 Sobre estas discrepancias véase: LAGARDE, G. DE, «Marsile de Padoue et Guillaume de Nogaret», Revue historique de droit français et étranger, $4^{\mathbf{a}}$ serie, 10 (1932), pp. 463-490; IDEM, La naissance de l'esprit laïque au déclin du Moyen Age, Marsile de Padoue, edición refundida y ampliada, vol. III, Le Defensor Pacis, Lovain-Paris, Nauwelaerts, 1970, p. 7, n. 22; DOLCINI, C., Introduzione a Marsilio da Padova, Roma-Bari, Laterza, 1995, pp. 58-66.

8 Por ejemplo, en un sermón de Clemente VI el 11 de julio de 1343; y el papa Juan XXII, en una carta de 4 de enero de 1331, llegaba a atribuir o a Ocham y M. de Cesena la autoría de cinco de los artículos del Defensor pacis condenados.

9 LAGARDE, G. de, «Marsile de Padoue et Guillaume d' Ockham», en Revue des sciences religieuses, 17 (1937), p. 171; lo repite DOLCINI, C., Introduzione a Marsilio, o. c., p. 46.

10 «Nos autem dicamus (...) legislatorem seu causam effectivam primam et propiam esse populum seu civium universitatem aut eius valenciorèm partem, per suam eleccionem seu voluntatem in generali civium congregacione per sermonem expressam..." (MARSILIUS VON PADUA, Defensor Pacis I,XII,3, edc. latina: SCHOLZ, R., Marsilius von Padua. Defensor Pacis, Hannover-Leipzig, Hahnsche Buchhandlung, 1932, p. 63, líneas 15-20. En adelante esta edición crítica se cita abreviada y por las iniciales: $D P$ I,XII,3 S, 63,15-20.

11 Véanse: GUGGENHEIM, M., «Marsilius von Padua und die Staatslehre des Aristoteles», en Historische Vierteljahrschrift, VII, 1904, pp. 350; STIEGLITZ, L., Die Staatstheorie von Marsilius von Padua. Ein Beitrag zur Kenntnis der Staatslehre im Mittelalter, Leipzig, Teubner, 1914, p. 28; SCHOLZ, R., «Marsilius von Padua und die Idee der Democratie», en Zeitschrift für Politik, 1 (1908), p. 64 y ss; RUFFINI-AVONDO, E., «Il Defensor Pacis di Marsilio da Padova», en Revista Storica Italiana, 41 (1924), p. 141; y BATTAGLIA, F., Marsilio da Padova e la Filosofia politica del Medio Evo, Firenze, Felice Le Monnier, 1928, pp. 83-87 y 109.

12 Marsilio llega a postular la unidad de un alma humana o «anima universitatis civium», que podría equivaler al intelecto agente universal único (DP I,XV,6, S 89,1-5).

13 GRIGNASCHI, M., «Indagine sui pasi del «commento» suscettibili di averre promosso la formazzione.di un averroismo politico», en DOLCINI, C. (ed.), Il pensiero politico del Basso Medioevo. Antologia di saggi, Bologna, Pàtron, 1983, pp. 311-312. El autor modera aquí su rechazo de la filiación averroísta mantenida por él en sus trabajos anteriores y sugiere que Marsilio sufrió una traumática influencia del nominalismo. 
A nuestro juicio, sigue siendo acertada la afirmación de Passerin d'Entrèves: «de tal influjo nominalista sobre el pensamiento marsiliano no se ha dado hasta ahora ninguna prueba concluyente ${ }^{14}$.

\section{LA UNIDAD DE LA CIVITAS}

El texto marsiliano, en el que más se podría apreciar una posible orientación nominalista, corresponde a la explicación de la unidad de la civitas:

«De lo dicho ya aparece de algún modo en qué consiste la unidad numérica de la ciudad o del reino (numeralis unitas civitatis aut regni), que esta unidad es unidad de orden (unitas est ordinis), no unidad absoluta (non simpliciter unitas), sino una cierta pluralidad de individuos (pluralitas aliquorum) que se dice una (una dicitur), o de los que se dice que son una cosa única, no por ser uno (non propter hoc quod unum numero sint) formalmente en virtud de alguna forma, sino que se dicen y son verdaderamente uno en número, con respecto al gobierno (principatum) al cual y por el cual se ordenan y gobiernan» ${ }^{15}$.

Gewirth atribuye a Marsilio una posición nominalista en este pasaje, por sostener que el Estado es el conjunto de hombres, que es uno por una «unity of order» ${ }^{16}$. También Quillet se apunta al carácter nominalista de la definición marsiliana de la unidad ${ }^{17}$. No se trataría de unidad sustancial o inherente, sino que de esa multiplicidad de individuos se predica que constituyen una unidad, como se dice un mundo y no muchos mundos $\mathrm{y}$, sin embargo, no hay una forma de mundo o no es el mundo uno formalmente, sino en cuanto que el conjunto de entes están ordenados o referidos a un único ente primero ${ }^{18}$.

14 PASSERIN D'ENTRĖVES, A., «Rileggendo il "Defensor pacis"», en Rivista storica italiana, 51 (1934), p. 35 .

15 DP I,XVII,11, S 119,3-10; traducción propia; L. Martínez Gómez traduce principatum como 'principio' (El Defensor de la paz, Madrid, Tecnos, 1989, p. 102); Quillet interpreta «pluralitas aliquorum» como «pluralidad de hombres», QUILLET, J., Le Défenseur de la Paix, Paris, Libraire Philosophique J. Vrin, 1968, I,V,6, p. 162; las traducciones italianas optan por «individuos»: «pluralità di individui» (VASOLI, C., Il Difensore della pace, Torino, Unione Tipografica-Editrice Torinese, $1960,2^{a}$ edc., 1975, p. 234) y «molteplicità di individui» (Il Difensore della Pace, traducción y notas de M. CONETTI, C. FIOCCHI, S. RADICE, S. SIMONETTA, Milano, Rizzoli, 2001, I, p. 245).

16 GEWIRTH, A., Marsilius of Padua. The Defender of Peace, vol. I: Marsilius of Padua and the Medieval Political Philosophy, London, Mc Millan, 1951, p. 116; sobre el nominalismo de Marsilio vuelve Gewirth más adelante, si bien con algunas matizaciones; véase, ibid., pp. 210 y 218.

17 QUILLET, J., Le Défenseur de la Paix, o. c., p. 162, nn. 26-27; y lo razona en QUILLET, J., La philosophie politique de Marsile de Padoue, o. c., pp. 68-69. Véase, asimismo, GRIGNASCHI, M., «L' Ideologia marsiliana si spiega con l'adesione dell' Autore all'uno o all'altro dei grandi sistemi filosofici dell'inizio del Trecento?», en Medioevo, 5 (1979), pp. 214-217.

18 «Unde nec sunt unum per aliquid formaliter inherens unum» (DP I,XVII, 11, S 119,15); "Quo eciam quasi modo mundus dicitur unum numero, non plures mundi, non quidem propter formam aliquam unicam numeralem formaliter universis entibus inherentem, sed propter numeralem unitatem primi entis dicuntur omnia encia unus mundus numero, quoniam encium quodcumque naturaliter inclinatur et pendet ab ente primo» (DP I,XVII,11, S 119,21$120,2)$; «los entes son muchos en cuanto a su naturaleza y se convierten en uno por analogía, en virtud del acto lógico de la predicación que los refiere a Dios», DI VONA, P., I Principi del «Defensor Pacis», Napoli, Morano, 1974, p. 236. Di Vona dedica el cap. IV de este libro a estudiar la aplicación marsiliana del principio di economía y concluye que carece de fundamento atribuir a Marsilio la posición nominalista de la conversión del conjunto de hombres en Estado sólo por una unidad de orden. A su juicio, el pasaje citado contiene la afirmación explícita de la analogia entis y la unidad de orden es para Marsilio una unidad de analogía que presupone en valor metafísico de la misma; véase, ibid., p. 237. Di Vona proyecta sobre Marsilio la defensa de la analogia entis sostenida por Juan de Jandún frente a los partidarios de la univocidad del ser y le atribuye el valor especulativo que le daba el averroís- 
No obstante, Marsilio va más allá del ejemplo de los entes que forman una unidad en cuanto son referidos a Dios y termina el párrafo con la afirmación de que los hombres de una ciudad constituyen una unidad o reino porque «quieren un único gobierno en cuanto a su número» ${ }^{19}$. De modo que podríamos decir que la unidad de autoridad se basa en el principio de unificación constituyente de la civitas y que el peso recae sobre la voluntad política constituyente. Por lo que el pensamiento de Marsilio derivaría de la aplicación a la política del principio nominalista de la superioridad de la voluntad sobre el entendimiento. Dejamos para otro momento el análisis del papel que corresponde a la razón y a la voluntad en la constitución de la civitas y la controversia sobre el positivismo de la filosofía marsiliana de la ley, querequieren más espacio y profundidad; y vamos a considerar sólo el individualismo social, característico del nominalismo, frente al carácter unitario de la civitas como un todo, más allá de la suma de sus ciudadanos individuales.

Marsilio parece sostener que es la unidad del representante («único gobierno») y no la del representado (única 'voluntad general') la que constituye la unidad política: la pluralidad de individuos se dice una, no por ser formalmente uno, «sino con respecto al gobierno, al cual y por el cual se ordenan y gobiernan». Pero la unidad de la que habla Marsilio tampoco es la unidad en la persona del gobernante, como en Hobbes, sino que se trata de la «unidad de acción (...) ya sea regida por un hombre, ya por muchos» y, a pesar de afirmar que «conviene que haya un único poder (...) único en número por encima de todos» y que el poder supremo «ha de ser de necesidad numéricamente uno», no significa que el poder tenga que reducirse a una persona física: «no ciertamente un gobernante único en número, según el supuesto de la especie humana, sino según el oficio» ${ }^{20}$. Marsilio carece aún de la mentalidad individualista del contractualismo moderno ${ }^{21}$, según la cual no sólo no se puede hablar de cuerpo político fuera de una acción representativa, sino que fuera de tal acción no tenemos ninguna realidad determinada, ninguna voluntad expresa que deba ser traducida en la esfera política: sólo la representación da forma y por ello existencia al cuerpo político y a su voluntad. En cambio, en Marsilio, la estructura corporativa de la universitas civium «no permite una radicalización genética del tema de la forma representativa», puesto que el populus aún no se concibe exclusivamente como un conjunto o multitud de individuos.

mo; véase, ibid., p. 247. Sin embargo, la expresión no es utilizada por Marsilio, posiblemente porque, a pesar de que Marsilio emplea abundantemente la analogía entre los hechos sociales y los fenómenos físicos y biológicos, evita emplearla en sentido moral o teleológico, como advierte GEWIRTH, Marsilius of Padua, I, o. c., p. 51. Marsilio combina el aristotelismo y la metáfora orgánica con el sistema epistemológico medieval de la analogía proporcional. Aunque, «cuando recurre a la analogia entis o a la superioridad del todo sobre las partes, estas fórmulas de perfil metafisico deben entenderse como premisas constructivas del discurso y no se deben confundir con el contenido especifico de su filosofia. Di Vona incurriría en esa confusióni»; véase, DOLCINI, C., Introduzione a Marsilio da Padova, Roma-Bari, Laterza, 1995, p. 36.

19 «Unius civitatis aut provincie homines dicuntur una civitas aut regnum, quia volunt unum numero principatum» (DP I,XVII,11, S 120,7-8). La expresión «quia volunt» es muy clara, pero la traducción española, atrapada por el paralelismo con el ejemplo de la referencia de los entes al ente primero, suprime el acento voluntarista que le da Marsilio y traduce: «dicha una por su referencia voluntaria a un principado», El Defensor de la Paz, Madrid, Tecnos, 1979, p. 103.

$20 D P$ I,XVII, 1, S 119,20-120,2. La necesaria unidad de poder implica en Hobbes la unidad de la persona del príncipe soberano: «la multitud, por naturaleza, no es una, sino muchos», por lo que «una multitud de hombres deviene una persona cuando son representados por un hombre", de modo que la unidad debe entenderse como "la unidad del representante y no la unidad de los representados», HOBBES, T., Leviatán, Madrid, Alianza Universidad, $2^{\text {a }}$ reimp., 1993, XVI, p. 137.

21 «No posee la gramática contractualista de base individualista que permite el corte radical del discurso de Hobbes», OMAGGIO, V., Marsilio da Padova. Diritto e Politica nel «Defensor Pacis», Napoli, Editoriale Scientifica, 1995 , p. 73 . o. c., p. 73. 


\section{EL SIGNIFICADO DE POPULUS}

Marsilio afirma que la «causa efectiva prima et propia» de la ley es el «populus seu civium universitas» ${ }^{22}$. El pueblo, del que surge la autoridad y la ley, es el conjunto de todos los ciudadanos (universitas civium) y, asimismo, la multitud ( $\left(m u\right.$ mititudo sive populus») ${ }^{23}$.

El uso de universitas implica una concepción de ésta cercana a la idea de un «corpus» (cuerpo, conjunto o totalidad), en el sentido de:remitir a derechos y obligaciones de todos los miembros en cuanto 'partes' del todo. Podría, por ello, asimilarse universitas al pueblo o conjunto de todos los ciudadanos, aunque sin comportar una concepción igualitaria y democrática en el sentido actual de estas expresiones. De hecho, en los romanistas universitas designa el pueblo ${ }^{24}$. Los glosadores identificaron casi unánimemente la corporación con sus miembros $^{25}$; sin embargo, más tarde, los comentadores no consideraban a estos hombres como individuos aislados (singuli), sino como una corporación humana, una visión ya anticipada por Azo. Y, en un sentido parecido, se emplea desde el siglo XII en el norte de Italia para designar la città o universitas civium. Marsilio considera la universitas civium como una entidad ${ }^{26}$, a diferencia de Ockham, que rechaza expresamente el concepto de los juristas persona ficta, y no concede a la asociación humana otro tipo de realidad que la de los seres humanos individuales que la componen.

Emplea a menudo también el término multitudo, sin reducir su significado al aspecto cuantitativo de grupo amplio o simple yuxtaposición de muchos. Multitudo no es muchedumbre, masa de gente, ni siquiera pueblo en general, sentido en el que se puede entender este término cuando lo encontramos en los autores inmediatamente predecedentes que lo usaron (Tomás de Aquino, Pedro de Alvernia, y, antes que ellos, Alberto Magno). En Marsilio multitudo es ya el conjunto de ciudadanos que, reunidos, son más que la suma de individuos y, por ejemplo, «la multitudo juzga mejor que un pequeño grupo» ${ }^{27} \mathrm{o}$ «manda en las cosas más importantes» ${ }^{28}$.

$22 D P$ I,XII,3, S 63,17. En este momento de la definición de ley, es también la primera vez que aparece populus con sustantividad propia. En las ocasiones anteriores el término se refería al «Romanus populus» (DP I,IX,10, $\mathrm{S} 47, \mathrm{I}$ ) o a los «populi iudices» (DP I,XI,6, S 59,22).

23 En el siguiente texto interpreta la frase de Aristóteles: «es justo que la multitudo ejerza la soberanía sobre asuntos más importantes (maiorum)» (Política, III,11, 1282a 18) del siguiente modo: «id est: iuste dominari debet de maioribus, que sunt in policia multitudo seu civium universitas (...) Vult dicere, quod omnium collegionum policie seu civilitatis simul sumptorum amplior est multitudo sive populus» (DP I,XIII,4, S 73,5-12; subr. nuestro).

24 «Universitas, id est populus, hoc habet officium singulis scilicet hominibus quasi membris providere» se lee en Quaestiones de iuris subtitulatibus, escritas al principio del siglo XII por autor desconocido; véase, PENNINGTON, K., «Law, legislation and government, 1150-1300», BURNS, J. H. (ed.), o.c., p. 443, n. 36.

25 Asi Accursio: la corporación no es otra cosa que los hombres que hay en ella («universitas nil aliud est nisi homines ibi sunt»), cit. por CANNING, J. P., «Law, sovereignty and corporation theory. 1300-1450», BURNS, J. H. (ed.), o.c., p. 474, n. 68 .

26 Canning se refiere a este origen y a la diferencia entre Marsilio y Ockham; véase, CANNING, J. P., o. c., p. 476; y Quillet se extiende más ampliamente en ella; véase, QUILLET, J, «Community, counsel and representation», o. c., pp. 563-565. Sobre la posible derivación de este concepto de fuentes jurídicas existe discusión: Wilks la defiende, mientras que Walter la refuta; véase: WILKS, M., «Corporation and representation in the "Defensor pacis"», en Studia Gratiana, 15 (1972), pp. 254-256; y WALTHER, H. G., Imperiales Königtum, Konziliarismus und Volkssouveränität. Studien zu den Grenzen des mittelalterlichen Souveränitätsgedankens, München, Wilhelm Fink Verlag, 1976, p. 162, n. 179. Más recientemente, Merlo afirma que Marsilio «no da el paso decisivo de la universitas a la persona ficta» y que la «universitas civium et fidelium» marsiliana sería anómala respecto al desarrollo de la idea jurídica de la personalidad de la corporación, que se da primero en el derecho canónico y luego en las teorias regalistas; véase, MERLO, M., «Pace, guerra e identità della comunità politica in Marsilio da Padova»; en SCATTOLA, M., (ed.), Figure della guerra. La riflessione su pace, conflitto e giustizia tra medioevo e prima età moderna, Milano, Franco Angeli, 2003, p. 129.

27. DP I,XIII,6, S 75. Tomado en el sentido en el que Aristóteles dice: «los más, cada uno de los cuales es un hombre mediocre, pueden sin embargo, reunidos, ser mejores que aquéllos, no individualmente, sino en conjunto... Por eso las multitudes juzgan mejor...» (Politica, III,1 1, 1281 b). 
Multitudo es el cuerpo de ciudadanos entendido por Marsilio como un todo, según la expresión empleada "universa multitudo civium»" ${ }^{29}$ : son los ciudadanos que actúan como una sola entidad - la universitas civium o el pueblo que constituye la civitas-, porque su unidad se expresa en la promulgación de la ley.

En el mismo parágrafo en el que se encuentra el texto manejado por los estudiosos tendentes a la interpretación nominalista, se afirma también: «la ciudad o el reino no es unorum en virtud de una forma natural única, ut composicionis aut commixcionis». El carácter unitario de la civitas no es el propio de una composición o mezcla, que forma una nueva sustancia, sino una 'relación' ${ }^{30} . \mathrm{Y}$, salvo en el pasaje estudiado, ambiguo y controvertido como vemos, no pueden identificarse otros ecos individualistas en la obra marsiliana. Diriamos que se muestra más interesado por las relaciones sociales, que por los sujetos de esas relaciones en cuanto sujetos individuales. En general, cuando habla del hombre no se refiere al hombre individual, sino a los hombres en su relación con la suficiencia de vida y con las necesidades humanas específicas, que exigen para su satisfacción la sociedad organizada; señala al ser humano o a las facultades humanas; es decir, designa lo universal o esencialmente humano, el género humano. Así, habla de «los hombres» o de lo «humano» en expresiones tales como: «humanum optimum, eius vite scilicet sufficienciam explicans» (DP I,I,1, S 5-6); «ad pacem habendam (...) voluntates hominum excitaret» (DP I,I,1, S 2,7-9); «humanus genus» (DP I,I,V, S 6,23; I,I,IV, S 19,6; I,V,2, S 21,17); «homines propter sufficienter vivere congregati» (DP $\mathrm{I}, \mathrm{I}, \mathrm{V}, \mathrm{S} 19,13$ ); «opportuit diversos ordines hominum seu officia in hac communitate (...) quibus pro vite sufficiencia homines indigent» (DP I,I,V, S 19,22-24); «humana mens» (DP I,I,7, S 34,21); «materia propria officiorum diversorum, secundum quod officia nominat habitus anime, sunt homines» (DP I,I,7, S 34,23-25). Tampoco las pocas veces que emplea «homo» en singular tiene un sentido individual o personal ${ }^{31}$.

$28 D P$ I,XIII,4, S 73,2-6. Parafrasea a Aristóteles: «De modo que es justo que la masa ejerza la soberania sobre asuntos más importantes», Politica, III,11, 1282 a 17.

29 «Lex data ex auditu et precepto universe multitudinis civium» (DP I,XII,6, S 67,4). El texto será analizado más adelante. Baste por ahora constatar el interés de Marsilio en precisar que la multitudo actúa como un todo. Lewis comenta que en el derecho corporativo se distingue entre «omnes ut singuli» y «omnes et universi», que sería este caso; véase, LEWIS, E., «The «positivism» of Marsiglio of Padua», en Speculum, 38 (1963), p. 567, n. 100.

$30 D P$ I,XVII, 1 1, S 119,11-12. Según Grignaschi, la expresión «unorum» recuerda a esta otra de Pedro de Alvernia: «Omnis enim pluralitas unicorum vel est acervus vel compositio. Sed relatio et fundamentum non faciunt acervum ergo compositionem», PEDRO DE ALVERNIA, In I Sent., dist. 30. El término «commixcio» tendría el mismo valor que «acervus», en cuyo lugar Duns Escoto emplea a veces «aggregacio». En todo caso, Marsilio no parece interesado en las discusiones sobre la relatio, que entonces era centro de atención de los teólogos y probablemente no había entendido todas las implicaciones de aquellos debates, a juzgar por la comparación con el ejemplo del mundo; véase, GRIGNASCHI, M., «L'ideologia marsiliana si spiega con l'adesione...», o. c., p. 216. Marsilio toma de Pedro de Alvernia la nueva teoría de la relatio que explicaba las relaciones entre el príncipe y los súbditos por compromisos voluntarios. Duns Escoto mantiene el principio de que la unidad del Universo no esta garantizada por una relatio real entre sus diferentes partes, sino por la Voluntad Divina; y, por analogia, Marsilio explica la «unitas principatus» por la voluntad de las communitates, que se someten a un único principans, y la formación de los «officia civitatis» por el «preceptum principis» que los instituye; véase, GRIGNASGHI, M., Reflexions suggerées par une dernière lecture du «Defensor pacis» de Marsile de Padoue», PELÁEZ, J. M. (ed.), Ciencia política comparada y derecho y economía en las relaciones internacionales. Serie Estudios interdisciplinares en homenaje a Ferrán Valls i Taberner, XVI, Universidad de Málaga, 1992, p. 4520.

31 «Homo nascitur compositus ex contrariis elementis (DP I,I,III, S 18,5). Sobre la concepción del hombre y su subordinación al conjunto de la comunidad, véase, GOGACZ, M., «L'homme et la communauté dans le $D e$ fenseur pacis de Marsile de Padue», en Medioevo, 5 (1979), pp. 189-200. 


\section{EL TODOY LAS PARTES}

Otro elemento que aleja claramente a Marsilio del individualismo nominalista es la apelación al principio de que «el todo es mayor que las partes», que acompaña a expresiones como «maior pluralitas» o «universa multitudo», en contraposición a lo hecho «per unum aut pau$\cos$ quosdam $)^{32}$, y que no deja lugar a dudas de la superioridad del conjunto. El conjunto de los ciudadanos, además de ser cuantitativamente mayor, tiene mayor capacidad cualitativa de discernimiento: «es verdadero tanto en la magnitud o la cantidad, como enla virtud práctica y la acción», que una cualquiera de sus partes. El todo es mayor que un grupo particular o minoría, por muy selecta que sea, no sólo en número o masa-lo cual es obvio-, sino «in activa virtute et actiones ${ }^{33}$, de modo que la totalidad de los ciudadanos es activa y actúa conjuntamente. De este principio se deduce necesariamente que «la totalidad de los ciudadanos, o su equivalente multitud prevalente, puede discernir sobre lo que se ha de elegir o rechazar mejor que cualquiera de sus partes» ${ }^{34}$. Por su parte, Olivieri considera que «el principio de la superioridad del todo sobre las partes asume el papel de soporte argumental básico de toda la concepción política de Marsilio»» ${ }^{35}$.

A diferencia de la concepción aristotélica, Marsilio toma explícitamente la noción de valentior pars como equivalente funcional de la totalidad, sin que sea posible, por consiguiente, una interpretación restrictiva de ella, como parte minoritaria o privilegiada que la reduzca a algo menor que el todo. No se puede reducir el alcance operativo de la totalidad y de su valentior pars a una parte restringida del cuerpo político concebida como el resultado de una extracción o selección del mismo. La parte prevalente «representa la totalidad de los ciudadanos», hace las veces de ella, se toma como la misma comunidad en su conjunto (pro eodem) y tiene la misma autoridad ${ }^{36}$ e incluso se identifica con ella. Es preciso entender que la universitas civium y su multitud prevalente (aut ipsius valencior multitudo) son lo mismo ${ }^{37}$. La valentior pars no es, por tanto, una de las partes de la civitas sino la comunidad entera en su representación; y el significado de valentior coincide con el de legislator. En tal sentido Marsilio sostiene la superioridad de la valentior pars sobre los individuos y los particulares. Si el todo no es homologable con ninguna de sus partes inferiores a él, la equivalencia entre el todo y la valentior pars impide considerar a ésta como una parte distinta o inferior a la universitas civium. Se trata, en definitiva, de una instancia de nivel superior al de todas aquellas partes, para las cuales Marsilio hace valer la correspondiente inferioridad respecto del todo, una instancia susti-

32 «...quoniam illius veritas cercius iudicatur, et ipsius communis utilitas diligencius attenditur, ad quod tota intendit civium universitas intellectu et affectu. Advertere enim potest magis defectum circa propositam legem statuendam maior pluralitas quacumque sui parte, cum omne totum corporeum saltem maius sit mole atque virtute qualibet sui parte seorsum. Adhuc, ex universe multitudine magis attenditur legis communis utilitas, eo quod nemo sibi nocet scienter. Ibi autem inspicere potest quilibet, an lex proposita magis declinet ad cuiusdam aut quorundam commodum quam aliorum vel communitatis, et in contrarium reclamare; quod non fieret si per unum aut paucos quosdam, proprium magis quam commune attendentes commodum, lex ipsa fertum (DP I,XII,5, S 66,3-16; las expresiones sui parte, omne totum y maius sit, en cursiva en el original).

$33 \quad D P$ I,XIII,2, S $71,22$.

$34 \quad D P$ I,XIII,2, S 71,23-26.

35 OLIVIERI, L., «Il tutto e la parte nel «Defensor pacis» di Marsilio da Padova», en Rivista [Critica] di Storia della Filosofia, 37 (1982), p. 65. En cambio, Lewis considera irrelevante en el Defensor pacis el significado de este tópico, frecuentemente empleado en las discusiones filosóficas medievales y lugar común entre los juristas del ius commune; véase, LEWIS, E., o. c., p. 567, n. 101. Sobre la importancia de este principio en la filosofia marsiliana, Di Vona advierte que «el principio de la superioridad del todo sobre la parte estaba en la tradición del averroísmo latino, pero también era aceptado, incluso celebrado, por sus adversarios curiales; y considera que nada es más interesante que constatar cómo Marsilio se sirve de este gran principio metafísico para conseguir construir una doctrina opuesta a la de la plenitudo potestatis; véase, DI VONA, P., o. c., p. 340

$36 \quad D P \mathrm{I}, \mathrm{XII}, 5, \mathrm{~S} 65,10-12$ y S 66,2-3.

37 «...que pro eodem accipienda sunt» (DP I,XIII,2, S 71,24-25). 
tutiva o equivalente del conjunto del pueblo. La autoridad legislativa pertenece al pueblo o a su parte prevalente, porque todos los hombres reunidos están en grado de obtener un conocimiento verdadero de lo que es justo o no $l o \mathrm{es}^{38}$.

\section{CONCEPCIÓN ORGÁNICẢ Y PERSPECTIVA FUNCIONAL}

La aplicación de la metáfora orgánica, junto con el principio clásico del todo y las partes; introduce en el significado de la totalidad la perspectiva de la función corporativa de la universitas: «omne totum corporeum». Esta perspectiva funcional y ontológica del cuerpo político resulta completamente ajena a la concepción individualista del nominalismo. Quizá influido por su formación médica, Marsilio compara la sociedad con un cuerpo vivo y representa constantemente la paz como la salud del cuerpo social. La paz se apoya en la buena disposición de las partes en la comunidad: así como el cuerpo viviente de un animal está compuesto de miembros y partes orgánicas, que se relacionan funcionalmente entre sí y con el conjunto del organismo, la ciudad se compone de partes que desempeñan distintas funciones para el buen funcionamiento del conjunto social; de modo que los órganos son al cuerpo animal lo que las partes u oficios son a la ciudad. Si la salud es la buena disposición del cuerpo viviente que procura el buen funcionamiento de los órganos, del mismo modo la paz depende de la buena ordenación de las partes de la ciudad para desempeñar adecuadamente sus respectivas funciones. Se dice que un cuerpo está sano, si cada parte cumple perfectamente sus funciones; y que hay paz, si las partes de la civitas cumplen las funciones que le son propias en virtud de la distribución constitucional ${ }^{39}$. El propósito de esta analogía es identificar al Papado como causa de la enfermedad, que es la guerra civil dentro de la sociedad cristiana, y situar el sacerdotium como un miembro más, entre otros muchos, del cuerpo único.

En el capítulo sobre la organización de la ciudad en diferentes partes, Marsilio describe cómo la razón inmanente a la comunidad engendra al organismo social, por imitación consciente del proceso de las fuerzas creadoras de la naturaleza ${ }^{40}$; y establece una correlación entre las partes de la ciudad y las funciones que procuran atender adecuadamente las diferentes necesidades de la comunidad. En el organismo natural, la naturaleza («causa movens») forma primero el corazón, como parte primera e indispensable, y lo dota de calor como fuerza peculiar suya, mediante el cual el corazón configura luego, como órgano apropiado para ello, todas las otras partes, las separa, las diferencia y enlaza, y después las mantiene, protege y restaura ${ }^{41}$. De similar modo, la totalidad social está dotada de un principio activo o fuerza actuante, el «anima universitatis vel eius valentioris partis» ${ }^{42}$, que es el principio creador de la civitas y

$38 D P$ I,XIII,2, S 71,5-26. En este punto puede verse alguna continuidad con la filosofia sobre la maior pars presente en las Quaestiones super metaphysicam de Jandún: «Ante la cuestión de si la mayor parte de los hombres puede alcanzar el conocimiento de la verdad, es necesario distinguir al individuo de la colectividad. Si decimos que el hombre individual esta capacitado para tener un conocimiento perfecto es falso (...) Ahora bien, si queremos resolver la cuestión en sentido colectivo, diremos que filosofía se convierte en ciencia perfecta en la mayor parte de los hombres reunidos juntos y todos llegan colectivamente a la verdad, porque uno posee una parte de ella y el otro otra y así sucesivamente», JUAN DE JANDÚN, Quaestiones in XII libros Methaphysicorum, f.4ra.

39 Esta correlación funcional aparece especialmente en $D P I, I$,3; véase, CANNING, J. P., «Power in Marsilius' Political Thought», en History of Political Thought, XX, 1 (1999), p. 32. Pero la analogía se reitera, incluso más explicitamente, en otros pasajes ( $D P$ I,VIII, I; I,XV,5; I,XVII,8-12; DP II,XXIV,12-13; II,XXX,1).

40 «Fuit autem in hoc humana sollicitudo convenienter imitata natura» (DP I,XV,5, S 87,20-21). Dedica este parágrafo y el siguiente a describir con prolijidad la analogía entre la naturaleza y la sociedad.

41 Vease ANCONA, E., «Il significato del cuore nella filosofia giuridica di S. Agostino e di Marsilio da Padova», en Rivista Internazionale di filosofia del diritto, 71 (1994), pp. 201-215.

42 Por ese principio activo se forma una parte análoga al corazón, el principado, en la cual la totalidad ha puesto una capacidad o autoridad de instituir las otras partes de la ciudad: «Nam ab anima universitatis civium aut eius 
sus partes («principium factivum civitatis»). Se trata, sin embargo, de un anima o principio racional ${ }^{43}$. Este principio es el mismo que establece la ley para todos y la autoridad exclusiva de juzgar ${ }^{44}$ : es el principio constituyente en el que radica la soberanía. Su acción produce en la civitas o reino, según el modelo de la naturaleza, en primer lugar, una parte primera o principal, más noble, que se corresponde con el corazón y le da una potencia activa comparable al calor: el poder de ordenar, ejecutar y juzgar. Al mismo tiempo, el principans debe recibir mediante la ley una regulación de su proceder, al igual que el corazón sólo puede actuar en la «forma seu virtus» determinada por la naturaleza. Y la función y el poder del príncipe no deben detenerse nunca para no poner en peligro la vida y la paz social, como no puede hacerlo la actividad del corazón, que garantiza la salud y la vida.

\section{CONCLUSIONES}

Por tanto, es cuanto menos dudoso que la teoría de la civitas que expone Marsilio esté basada en una concepción nominalista de la sociedad. La postura de Marsilio se asemeja a la de Ockham en los presupuestos críticos: la lucha contra la plenitudo potestatis del Papado. Pero difiere, entre otros aspectos, en que quiere liberar completamente a la comunidad política de ese poder destructivo y asegurar la libertas de la civitas en su conjunto, mientras que Ockham atiende más, por razón de su filosofía nominalista y de su vocación franciscana, a la libertad de los individuos. Marsilio «mira sobre todo a construir una civitas que se sustraiga a su [de la plenitudo potestatis] peso e influjo, estructurándola de modo que no quepa en ella el poder eclesiástico. De ese modo se garantiza la libertad de la civitas, pero no puede decirse lo mismo de respecto de las personas individuales» ${ }^{45}$. Esta diferente motivación conduce a dos modelos de sociedad distintos: el de Ockham, más pluralista, tanto en el seno de la Iglesia como de la comunidad política; el de Marsilio, mucho más monolítico, en el sentido de que no reconoce para los ciudadanos o las partes de la civitas capacidad para actuar autónomamente, sino al dictado de lo que indica la ley, cuyo contenido concreto ha quedado al final en manos del principans.

Otra consecuencia del diferente planteamiento que tienen Marsilio y el nominalismo acerca de la base social de la communitas christiana es la discrepancia de Ockham hacia la teoría de la infalibilidad del Concilio general. Para el Paduano, el Concilio general es infalible en un sentido en que no pueden serlo los sacerdotes ni los obispos tomados individualmente. Sólo a través del Concilio se puede acceder a la verdad religiosa de la ley divina, como sólo a través del consenso se fundamenta la justicia social expresada en la ley humana. A Ockham esta concepción de la infalibilidad conciliar le parecía un residuo metafísico o, simplemente, una expresión de misticismo; y la atacó, a finales de la década de 1330, en la III ${ }^{\mathrm{a}}$ parte del Dialogus, el De potestate papae et cleri, con la afirmación de que nadie, ningún individuo ni congrega-

valencioris partis formatur aut formari debet in ea pars una primum proporcionata cordi, in qua siquidem virtutem quandam seu formam statuit cum activa potencia seu auctoritate instituendi partes reliquas civitatis. Hec autem pars est principatus, cuius quidem virtus causalitate universalis lex est et cuius activa potencia est auctoritate iudicandi, precipiendi et exequendi sentencias conferencium et iustorum civilium) (DP I,XV,7, S 89,1-8).

43 «Hits autem proporcionaliter contemplandum in civitate convenienter instituta secundum rationem» (DP I,XV,6, S 88,24-25). Sobre esta comparación llamó la atención GIERKE, O., Teorías politicas de la Edad Media, Madrid, Centro de Estudios Constitucionales, 1995 p. 133, n. 99.

44 «Statuit principium activum civitatis, anima videlicet universitatis, in hac prima parte virtutem quandam causalitate universalem, legem scilicet, auctoritatem quoque seu potestatem agendi secundum illam iudicia civilia, precipiendi et exequendi de hiis, non aliter» (DP I,XV,7, S 90,6-10).

45. En cambio, a Ockham «le mueve el amor a la libertad, que tiene en el alma humana y en el Evangelio su doble raíz», DAMIATA, M., «Plenitudo potestatis» $e$ «universitas civium» in Marsilio da Padova, Firenze, Edizioni Studi Francescani, 1983, p. 289. 
ción de individuos, puede penetrar en la sabiduría divina y desentrañar sus designios; y que, por consiguiente, el Concilio no es menos falible que los miembros individuales que lo componen. A lo cual Marsilio responde, en el capítulo XII del Defensor minor, que lo que no puede ser llevado a cabo por una persona individual a menudo se puede conseguir por la cooperación de muchos y que, en el caso del Concilio general, la cooperación en la discusión y en la mutua educación produce como resultado un consenso sobre la verdad ${ }^{46}$.

En realidad, ningún pensador medieval elaboró una doctrina calificada 'nominalismo político', pues «ningún pensador habría reivindicado una doctrina titulada así», ni probablemente habría pretendido elaborar una filosofia política distinta de una filosofia que englobara el conjunto del saber, como reconoce la propia Quillet en un artículo específicamente dedicado a esta expresión ${ }^{47}$. El término mismo de nominalismo, que se debe a sus adversarios políticos, no surgió hasta 1339; por lo que resulta muy posterior al Defensor pacis, concluido en 1324 , e incluso, en gran medida, a la doctrina de Ockham. Por otra parte, parece exagerado deducir una teoría política a partir de la querella sobre los universales ${ }^{48}$, puesto que el nominalismo o el realismo ontológicos no se traducen automáticamente en concepciones políticas correlativas y opuestas.

Por último, hemos de tomar con cautela la declaración de que el nominalismo sienta los cimientos del individualismo liberal moderno o es el padre de los derechos naturales ${ }^{49}$. Quillet, para concluir su artículo ${ }^{50}$, asevera que pertenece al nominalismo político toda doctrina que considere que la comunidad política no es más que una colección de individuos, el bien común no es sino la suma de los bienes particulares y que, fuera de la mente, sólo existen individuos

46 «Si uno cualquiera no puede por sí solo, sin ayuda de otros, llevar una nave, o realizar otra acción semejante, de ahí no resulta que no lo pueda conseguir una multitud actuando junta y simultáneamente. Así también, del mismo modo o de manera similar, en un concilio la multitud de fieles actúa conjuntamente: pues escuchándose unos a otros, sus espíritus se incitan mutuamente a una determinada consideración de la verdad, a la cual ninguno de ellos llegaría estando solo o separado de los demás: además, ese parece haber sido el mandato divino y así se actuaba en la Iglesia primitiva», Defensor minor, XII,5, en JEUDY, C.-QUILLET, J., Marsile de Padoue. Oeuvres mineures, Paris, Centre National de la Recherche Scientifique, 1979, p. 260.

47 QUILLET, J., «Nominalismo político», en RAYNAUD, Ph. y RIALS, S. (eds.), o. c., p. 566; véase también, BLACK, A., o. c., pp. 601-602.

48 Ejemplo de explicación de la teoría política desde la adscripción a una escuela filosófica es la correlación mecánica que establece Guenée: «Los publicistas habían sido en general formados por la filosofia; por ello, su posición política se explica a menudo por su posición filosófica. Citemos como ejemplo (...) a los realistas, convencidos de la realidad de las ideas generales - de los universales - y a los nominalistas, para los que sólo existía lo individual; pues bien, esta querella determinó extraordinariamente una serie de oposiciones políticas: mientras que un realista sacrificaba gustoso la parte al todo, y el individuo al Estado, para un nominalista como Guillermo de Ockham lo esencial era el individuo y el bien común no era más que la adición de los bienes particulares. Las corrientes 'democráticas', que caracterizaron los siglos XIV y XV y que pusieron el concilio frente al Papa y los estamentos frente al príncipe, coincidieron con un renacimiento del nominalismo. $Y$ de esta forma, los publicistas difundieron unas opiniones que eran con frecuencia la traducción política de una reflexión filosófica», GUENÉE, B., Occidente durante los siglos XIV y XV. Los estados, Barcelona, Labor, $2^{\mathrm{a}}$ edc. 1985, pp. 37-38. Aunque reconoce el peso de la formación filosófica de estos autores, De Libera critica semejante paralelismo entre corrientes «democráticas» (individualistas y conciliaristas) y nominalismo por un lado, frente a teólogos defensores del poder absoluto que mantendrian el realismo en la cuestión de los universales; véase, DE LIBERA, A., «Le troisième pouvoir. Les intellectuels scolastiques et la politique», en Les philosophies morales et politiques au Moyen Age, Actes du IXe Congrès International de Philosophie Médiévale, Ottawa, 1992, pp. 257-258.

49 Algunos encuentran en Ockham, por su nominalismo, el origen de las actuales teorias contractualistas: la relevancia que da a los individuos singulares sentaría las bases para desvincular la comunidad de individuos del «universal» $\mathrm{y}$, desprendidos ya los conceptos políticos de su sentido onto-teológico, la fuente dimanante de su sentido quedaría exclusivamente en manos de la convención; véase, BECKMAN, J., Wilhelm von Ockham, Münich, Becksche Reihe, Beck Verlag, 1995, pp. 26-28. Beckman no lo afirma y deja abierta la pregunta.

50 QUILLET, J., «Nominalismo político», en o. c., p. 572. En dicho artículo analiza también, bajo tal denominación., el pensamiento del cardenal Pedro de Ailly, sobre el cual véase también: IDEM, «Les doctrines politiques de Pierre d'Ailly), en Miscellanea Mediaevalia, 9 (1974), pp. 345-358. 
que constituyen un cuerpo político por un proceso contractual nacido de su libre voluntad. Según esta definición, cabría calificar de nominalismo político a todo el liberalismo moder$\mathrm{no}^{51}$. Sin embargo, la división entre virtud cívica y libertad de los ciudadanos individuales no está presente en el pensamiento de los autores medievales ${ }^{52}$. En todo caso, la filosofía del $D e-$ fensor pacis no se preocupa de hacer compatibles la virtud republicana y el individualismo moderno, como rasgos de los gobiernos moderados y de las sociedades sanas. La universitas civium marsiliana nace de una tradición diferente del nominalismo y estaría más cerca del republicanismo clásico, previo a la consagración moderna del concepto de derechos individuales.

\section{Bernardo Bayona} bbayona@aragon.es

51 El individualismo sería el resultado necesario del nominalismo político, mientras que las teorias colectivistas tendrian sus orígenes en la tradición "realista» («esencialista» en la denominación de Popper, que resultaría más apropiada para esta interpretación); véase, PRIBAM, K., Die Entstehung der Individualistichen Sozial Philosophie, Leipzig, 1912. En él se apoya el neoliberalismo de finales del siglo pasado; véase, HAYEK, F. A., «Individualismo: el verdadero y el falson, XII ${ }^{2}$ Finlay Lecture en la University College de Dublín, Dublín y Oxford, 1946; reed en Individualism and Economic Order, The University of Chicago, 1948, reimpr. Gateway Editions, Ltd., South Bend, Indiana; en castellano, en Estudios Públicos, 22 (1986).

52 La separación entre virtud, característica del republicanismo, e interés propio, típico del liberalismo, es posterior. Pese a que Carr considera que la semejanza entre Marsilio, Maquiavelo y Locke podría extenderse a Thomas Jefferson; véase, CARR, D., «Marsilius of Padua and the Role of Law», en Italian Quarterly, 28 (1987), pp. 5 y 20 21. Las concepciones contractualistas modernas insisten en que, si deseamos maximizar nuestra libertad, es irracional conceder al bien común la mayor prioridad; mientras que las teorías del republicanismo clásico consisten precisamente en situar el ideal del bien común por encima de todas las consideraciones inspiradas en el beneficio individual y son incompatibles con la suposición de que el libre juego (la deliberación, la negociación o el mercado) garantizan mejor la libertad de todos y la vida buena; véase, SKINNER, Q., «Acerca de la justicia, el bien común y la prioridad de la libertad», La Política, 1 (1996), p. 141-149. Por su parte, Pocock da preeminencia al papel del 'humanismo cívico' italiano en la formación de las actitudes 'republicanas' occidentales (que enfatizan las virtudes políticas adquiridas mediante una implicación activa en sistemas de autogobierno), frente a las escuelas que sitúan el origen de la tradición occidental en Locke y en el individualismo que persigue el interés propio más que la moralidad cívica; véase, POCOCK, J. G. A., El momento maquiavélico, Madrid, Tecnos, 2002. 